\title{
KNOWLEDGE ABOUT TUBERCULOSIS OF PEOPLES LIVING IN EASTERN PART OF NEPAL.
}

\author{
Ram Hari Ghimire and Sita Ghimire
}

\begin{abstract}
:
\end{abstract}
Background: Tuberculosis is the major public health problem in the world; it is a major cause of illness and death worldwide especially in Asia and Africa.

Objective: To identify people knowledge about tuberculosis in Sonapur VDC.

Methodo ogy: Cross sectional study design, census, structured and semi structured questionnaire were used to collect respondent knowledge about tuberculosis.

Resu ts: This descriptive study included 2008 households, 9933 population of Sonapur Village Development Committee (VDC) lies in eastern part of Nepal. Among the respondent, $64 \%$ have heard of tuberculosis, and among them $64 \%$ think tuberculosis is caused due to smoking. In response to the symptoms of tuberculosis, $47 \%$ of the respondent said cough for more than two weeks and $24 \%$ said haemoptysis. Similarly, $72 \%$ of the respondent $(n=2008)$ said TB is transmitted from one person to another and $75 \%$ of the respondent who have heard of TB said TB is curable. In response to the treatment procedure, $94 \%$ of the respondent didn't have heard of DOTS, while $64 \%$ said the duration of treatment is 6 months.

Conc usion: The study found that the respondent has satisfactory knowledge about the cause of TB, sign and symptoms of tuberculosis. They have also satisfactory knowledge regarding transmission of tuberculosis; few of them know that it is curable. However, their knowledge about Directly Observed Treatment Short Course (DOTS) (treatment method) was very low. It is recommended that national tuberculosis control authority should design health education programme focusing on preventive methods (DOTS), duration of treatment and prevention of tuberculosis. The awareness campaign should be targeted to head of the household, women, community health care provider and should be disseminated through the media that will reach to the general public. Such awareness campaign will increase people knowledge about the disease and will help to reduce the drug resistant and improve the efficacy of DOTS programme.

Key Words: TB, DOTS, Mycobacterium Tuberculosis, Census.

\section{INTRODUCTION}

Tuberculosis (TB) is a major public health problem in the world and it is a cause of illness and death worldwide, especially in Asia and Africa. According to the World
Health Organization (WHO), one third of the world's population has been exposed to the tuberculosis pathogen ${ }^{1}$. By the end of 2011, 202 of 212 countries and territories had reported case notifications for 2010 and/or treatment outcomes for patients registered in 
2011. These countries include $99.6 \%$ of the world's population. Surveillance and survey data has estimated that 9.2 million new cases of TB occurred in 2010 (139 per 100, 000), including 4.1 million (62 per 100 000) new smear-positive cases. In terms of incidence, among the top five countries, India ranks first followed by China, Indonesia, South Africa and Nigeria. In 2011, Asia (South-East Asia and Western Pacific regions) accounted for $55 \%$ of global cases Africa 31\% and other three regions accounted for remaining fraction of cases ${ }^{2}$.

Among the 9.2 million new cases of TB in 2010 , it is estimated that around 709000 $(7.7 \%)$ were HIV-positive. This estimation is based on the global estimates of HIV prevalence among the general population (all ages) published by the Joint United Nations Programme on HIV/ AIDS (UNAIDS) and WHO in December $2010^{3}$. Tuberculosis is also the world's greatest infectious killer of women of reproductive age and the leading cause of death among people with HIV/AIDS ${ }^{4}$. The rise in HIV infections and the neglect of TB control programs have enabled a resurgence of tuberculosis ${ }^{5}$.The emergence of drug-resistant strains has also contributed to this new epidemic. From 2000 to 2004 it is estimated that $20 \%$ of TB cases are resistant to standard treatments and $2 \%$ resistant to second-line drugs ${ }^{6}$.The incidence of $\mathrm{TB}$ varies with age. In Africa, TB primarily affects adolescents and young adults ${ }^{7}$ However, in countries where TB has gone from high to low incidence, such as the United States, TB is mainly a disease of older people, or of the immunocompromised ${ }^{8,9}$. There are a number of known factors that make people more susceptible to TB infection: HIV infection is one of the most important factors for susceptibility to $\mathrm{TB}$ infection as in Sub-Sahara African countries where the incidence of HIV is high 10, 11 Smoking more than 20 cigarettes a day is said to increases the risk of $\mathrm{TB}$ by two to four times $^{12,} 13$ Diabetes mellitus is also an important risk factor that is growing in importance in developing countries ${ }^{14}$ Other disease states that increase the risk of developing tuberculosis are Hodgkin lymphoma, end-stage renal disease, chronic lung disease, malnutrition, and alcoholism ${ }^{16 .}$

Tuberculosis (TB) is a major public health problem in Nepal. About 45 percent of the total population is infected with $\mathrm{TB}$, of which 60 percent are adult. Every year, 40,000 people develop active TB, of whom 20,000 have infectious pulmonary disease ${ }^{17}$. These 20,000 are able to spread the disease to others. Treatment by Directly Observed Treatment Short course (DOTS) has reduced the number of deaths; however 5,000-7,000 people still die per year from TB ${ }^{18}$. Expansion of this cost effective and highly successful treatment strategy has proven its efficacy in reducing the mortality and morbidity in Nepal. By achieving the global targets of diagnosing 70 percent of new infectious cases and curing 85 percent of these patients will prevent 30,000 deaths over the next five years. High cure rates and Sputum conversion rate will reduce the transmission of TB and lead to a decline in the incidence of this disease, which will ultimately help to achieve the goal and objectives of TB control. DOTS have been successfully implemented throughout the country since April $2001{ }^{17}$. The NTP has coordinated with the public sectors, private sectors, local government bodies, I/NGOs, social workers, educational sectors and other sectors of society in order to expand DOTS and sustain the present significant results achieved by NTP. By 16th July 2011 NTP has 1,118 DOTS treatment centers with 3,103 sub centers. The treatment success rate stands at 90 percent and case finding rate of 73 percent. At the national level 36,951 TB patients have been registered of whom 15,000 infectious (sputum smear positive new cases) and are 
being treated under the DOTS strategy in

\section{OBJECTIVES}

The objective of the study was to determine Sonapur people's knowledge about tuberculosis.

\section{METHODS}

The present cross sectional study was carried out among the Sonapur VDC people which are lies in the eastern part of Nepal. The study carried over the period 19 March to 4 April 2012. A structured and semi-structured questionnaire were prepared in English and translated in Tharu language (local) as the tool for the data collection. The studies objectives and methods were explained to the head of the household and verbal consent was established before collecting the data. Census method was applied and hence $100 \%$ of the household were visited for data collection. For the study close ended questionnaire based on the knowledge about tuberculosis were used for interview by trained enumerators. There was all together 90 enumerators including 60 BDS and 30 BSC Nursing Students.

The questionnaire consist of background characteristics of population, knowledge of tuberculosis like its cause, symptoms, communicability, virulence, pathogenicity, cure, preventive methods, DOTS and treatment. Data was analyzed by using SPSS 15.0 version and the findings were presented by tables and diagrams.

\section{RESULTS}

The majority $(64 \%)$ of the respondents were heard about the tuberculosis (figure 1).

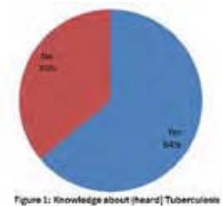

NTP during the FY 2067/68 (2010/2011) ${ }^{17}$

This shows that the majority of the population still lacks the general knowledge about tuberculosis. Among the respondents who have heard of tuberculosis, majority (64\%) said tuberculosis is caused due to smoking, while $5 \%$ said it due to dust. Almost $10 \%$ of respondent said TB is caused by the other factors like alcohol, bidi, pan and khaini etc

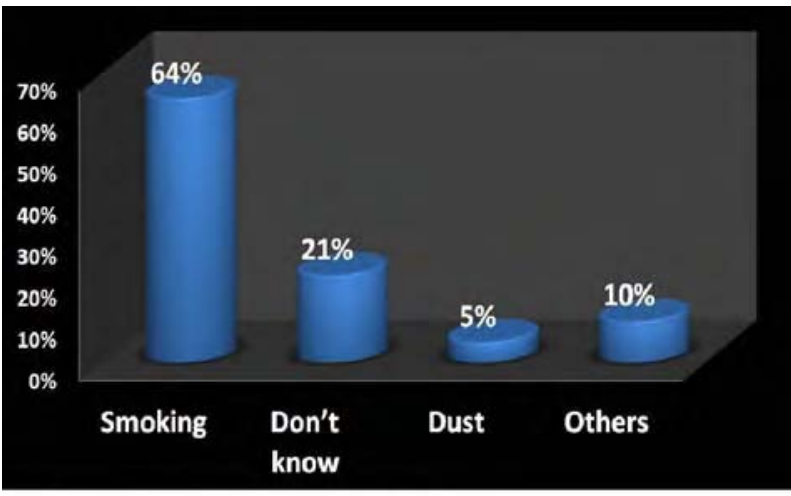

Figure 2: Knowledge on causes of TB

(Figure 2)

Knowledge on the clinical symptoms of tuberculosis, almost half (47 \%) answered chronic cough, followed by blood in sputum (24\%), fever $(13 \%)$ and chest pain $(7 \%)$. Above these all $9 \%$ of the respondents lack knowledge of symptoms of tuberculosis (Figure 3).

Similarly, majority $(72 \%)$ of the respondents

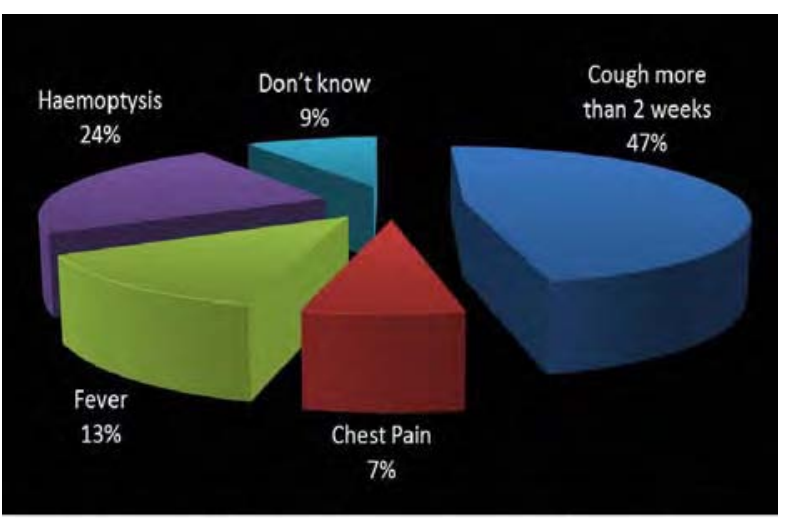

Figure 3: Knowledge on clinical symptoms of tuberculosis have knowledge that tuberculosis is infectious diseases while $19 \%$ of the respondent didn't know about TB transmission. 
The respondents have good knowledge (75 $\%)$ that tuberculosis is curable, however the knowledge regarding Direct Observed Therapy Short course (DOTS) was very poor (6\%).

Table 1

\begin{tabular}{|l|c|c|c|}
\hline & Yes $\%$ & No $\%$ & Don't Know \% \\
\cline { 3 - 4 } Is TB transmitted & 72 & 9 & 19 \\
\hline Is TB curable & 75 & 8 & 17 \\
\hline Heard of DOTs & 6 & 94 & \\
\hline
\end{tabular}

Table 1: Knowledge about TB transmission and treatment

\section{DISCUSSION}

The finding of the study showed that majority (64\%) of the respondent have heard about TB, this finding is consistent with the earlier finding of $\operatorname{Bam}(2003)$ where $60 \%$ of respondent heard about $\mathrm{TB}{ }^{17}$. This finding suggests that TB knowledge is low among the Sonapur VDC's people. For the government targeted linked to MDGs and endorsed by the Stop TB Partnership. It had been found that majority of the respondents $(82 \%)$ were aware of tuberculosis symptoms such as coughing $(82 \%)$, fever in the evening $(74 \%)$ and blood in sputum $(72 \%)$. These findings are significant for future intervention in $\mathrm{TB}$ control because sociological studies carried out in India have shown that an overwhelming majority of patients of pulmonary tuberculosis have one or more of the Symptoms referable to chest, such as persistent cough and fever, and many of them (over 60 per cent ) seek medical advice on their own initiative. The chest symptoms often develop early, that is before the disease has gone on to an advanced stage ${ }^{18}$.

Knowledge on the transmission of tuberculosis showed that only $50 \%$ of patients knew that tuberculosis is infectious disease transmitted by droplet infection ${ }^{19}$. Only $32 \%$ of respondent knew that use of mask by TB patient can prevent Tuberculosis. A similar study conduct by Joshi et al. (2006)22 showed that out of 58 respondents 28 were of the view that to prevent the transmission of $\mathrm{TB}$ it is advised not to sleep in a common place and 32 said transmission could be prevented by covering their mouth while coughing. Above findings of this study suggests that more emphasis should be given on teaching patients on mode of transmission of TB bacilli and using mask to prevent transmission of TB, because use of face mask by TB patients decreases the risk of transmission of $\mathrm{TB}$ infection to others. Regarding the transmission of tuberculosis $50 \%$ of the respondents knew correctly that $\mathrm{TB}$ is transmitted through droplet infection (Knowledge on the clinical symptoms of tuberculosis, majority (82\%) answered chronic cough, followed by fever (74\%), blood in sputum $(72 \%)$ loss of weight $(50 \%)$ and loss of appetite $(50 \%)$. This shows that two third of the respondent knew the common symptoms of Tuberculosis ${ }^{20}$. This finding is similar to the Sonapur VDC where 64\% respondent who heard about tuberculosis among them they respond the clinical symptoms of $(47 \%)$ said cough more than 2 weeks, $(24 \%)$ said haemoptysis ,(13\%) said fever, $(9 \%)$ don't know and $(7 \%)$ chest pain.

\section{CONCLUSION}

The study concluded that only $64 \%$ of the respondents have heard of TB. Although this is not promising still there is room for improvement. Health education targeting head of the households, females, FCHV is essential. Awareness campaigns regarding TB involving mass media and through health care providers can be helpful and beneficial in prevention and spread of TB. Over all findings of the study suggests that health education and awareness program for TB patients should be strengthened and it should contain all aspect of the TB prevention. This study is done only in one VDC so the findings and recommendations should not take for the whole of Nepal. Further study is 
recommended to develop a general guideline for developing awareness campaign and health education for TB knowledge to the whole nation.

\section{REFERENCES}

1. Nationa Institute of A ergy and Infectious Diseases (NIAID).[2] 26 October 2005. Retrieved on 3 October 2006.

2. Wor d Hea th Organization (WHO). Tuberculosis control, surveillance, planning, financing. World Health Organization, 2011.

3. AIDS epidemic update. 2010. Geneva, Joint United Nations Programme on HIV/AIDS and World Health Organization, 2007.

4. Stop TB Partnership. London tuberculosis rates now at Third World proportions. PR Newswire Europe Ltd. 4 December 2002. Retrieved on 3 October 2010.

5. Iademarco MF and Castro KG. Epidemiology of tuberculosis. Seminars in respiratory infections. 2007; 18 (4): 225-40

6. Emergence of Mycobacterium tubercu osis with extensive resistance to second-ine drugsworldwide, 2000-2004.

7. MMWR Morb Morta Wk y Re; 2008: 55 (11): 301-57. Wor d Hea th Organization (WHO). 2006. Global Tuberculosis Control Report, 2006 Annex 1 Profiles of high-burden countries. (PDF). Retrieved on 13 October 2006. Richard N. Robbins Basic Pathology (8th ed.) 2007. Saunders Elsevier. pp. 516-522

8. Centers for Disease Contro and Prevention (CDC). 2005. Surveillance Slide Set. (September 12, 2006) Retrieved on 13 October 2006.

9. Wor d Hea th Organization (WHO). 2006. Global tuberculosis control - surveillance, planning, financing WHO Report.Retrieved on 13 October 2006
10. Chaisson RE and Martinson NA. Tuberculosis in Africa-combating an HIV-driven crisis. N Engl J Med. 2008: 358 (11): 1089-1092.

11. Davies PDO, Yew WW and Gangu y D. Smoking and tuberculosis: the epidemiological association and pathogenesis. Trans R Soc Trop Med Hyg. 2006: 100: 291-8.

12. Jha P, Jacob B and Gaja akshmi V. A nationally representative case-control study of smoking and death in India. N Engl JMed; 2008: 358 (11): 1137-1147.

13. Restrepo BI. 2007. Convergence of the tuberculosis and diabetes epidemics: renewal of old acquaintances. Clin Infect Dis. 2007; 45: 4368.

14. SAARC Tubercu osis and HIV/AIDS centre. Tuberculosis in the SAARC region, an update. SAARC Tuberculosis and HIV/AIDS centre, Kathmandu Nepal.2007.

15. Park. K. Park's textbook of preventive and socia medicine. Twenty edition Publisher $\mathrm{M} / \mathrm{s}$ Banarsidas Bhanot 1167, Prem Nagar, Jabalpur, 482001 India 2007 p 159-175.

16. Bam T S. Factors affecting patients' compliance with directly observed treatment short course in Kathamndu urban areas, Nepal. Thesis submitted to master of primary health care management faculty of graduate studies Mahidol University Thailand.2003.

17. SAARC TB centre. Gender differences among TB patients in NTPs within SAARC member countries. SAARC TB Centre, Kathmandu Nepal. January 2002.

18. Sudre P, ten Dam G and Kochi A. Tuberculosis: a global overview of the situation today. Bull WHO. 1992; 70: 149-59.

19. Parrish NM, Dick JD and Bishai WR. 1998. Mechanism of latency in Mycobacterium tuberculosis trends. Microbiol;1998: 6: 107-12.

20. Roui on A, Perdrizet S and Parrot R. 1976. Transmission of tubercle bacilli: the effect of chemotherapy. Tubercle; 1997: 57: 275-99.

Address of correspondence: Ram Hari Ghimire, Lecturer, Department of Internal Medicine

Nobel Medical College, Biratnagar-5, E-mail: drsita42@yahoo.com 